\title{
Diagnóstico laboratorial da neurocisticercose: revisão e perspectivas
}

\author{
Laboratory diagnosis of neurocysticercosis: review and perspectives
}

Silvia Yukari Togoro'; Edna Malona de Souza ${ }^{2}$; Neuza Satomi Sato ${ }^{3}$

unitermos

Neurocisticercose

Taenia solium

Cysticercus cellulosae

Diagnóstico laboratorial

unitermos
Neurocisticercose
Taenia solium
Cysticercus cellulosae
Diagnóstico laboratorial

\section{resumo}

A neurocisticercose é causada por Cysticercus cellulose, a forma larval de Taenia solium, quando este se aloja no sistema nervoso central. O seu diagnóstico é realizado com base em dados clínicos, epidemiológicos, demonstração do agente etiológico pelas técnicas de imagem e testes laboratoriais. No presente estudo, apresentamos uma revisão do diagnóstico laboratorial, com ênfase no desempenho dos testes para pesquisa de anticorpos específicos e detecção de antígenos circulantes, utilização de antígeno homólogo ou heterólogo, nativo e recombinante, bem como a aplicação de métodos moleculares.

\section{abstract}

Neurocysticercosis is caused by Cysticercus cellulosae, the larval form of Taenia solium, when it lodges in the central nervous system. The diagnosis of neurocysticercosis is based on clinical and epidemiological data, neuroimaging findings of etiological agent and serologic test results. Herein we present a review of clinical diagnosis, emphasizing test performance for specific antibody and antigen detection, the use of homologous or heterologous antigen, native and recombinant antigens as well as the application of molecular methods.
Primeira submissão em 30/01/12 Última submissão em 30/01/12 Aceito para publicação em 19/03/12 Publicado em 20/10/12 (1) 


\section{Introdução}

A cisticercose humana representa importante problema de saúde pública em áreas carentes de condições sanitárias e de políticas de saúde pública, bem como em países desenvolvidos que recebem imigrantes de regiões de elevada prevalência de teníase.

O ciclo biológico do complexo teníase-cisticercose envolve o ser humano como único hospedeiro do verme adulto denominado Taenia solium, que, ao eliminar ovos nas fezes, contamina o meio ambiente. No suíno, após ingestão dos ovos, o embrião liberado no intestino delgado atravessa a mucosa e desenvolve-se até a forma larvária nos tecidos e nos órgãos, determinando a cisticercose. A forma larvária de T. solium é denominada Cysticercus cellulose. Completando o ciclo, o ser humano ao ingerir carne suína com cisticercos viáveis desenvolve a teníase, que é a presença de verme adulto no intestino(87).

Essa parasitose pode ocorrer acidentalmente quando 0 indivíduo ingere água e alimentos contaminados com os ovos de T. solium. Os cisticercos foram observados no globo ocular, nos músculos e no sistema nervoso central (SNC), sendo a neurocisticercose a forma mais grave da doença. Foram descritos três estágios prinicipais dos parasitas: vesicular (viáveis), coloidal (degenerativo) e calcificado (inativo) ${ }^{(33)}$.

O diagnóstico da neurocisticercose pode ser realizado pela demonstração conclusiva do cisticerco: detecção do parasita por técnicas histopatológicas em material de biópsia de uma lesão cerebral ou medular; visualização do escólex por tomografia computadorizada (TC) ou ressonância magnética (RM); e exame de fundo de olho, em casos de cisticercose intraocular ${ }^{(22)}$. Na impossibilidade de demonstração direta do parasita, os testes laboratoriais e a análise em conjunto de dados clínicos e epidemiológicos permitem o diagnóstico da doença na maioria dos $\operatorname{casos}^{(34)}$.

Os exames de imagens como TC e RM são ferramentas consideradas por alguns autores como padrão-ouro no diagnóstico da neurocisticercose, pois permitem a visualização de estruturas do parasito e do processo reacional do hospedei$\mathrm{ro}^{(6,16)}$. A TC apresenta maior sensibilidade na detecção de cisticercos calcificados, enquanto a RM possui maior poder de resolução, podendo evidenciar melhor o escólex e os cisticercos de localização ventricular ${ }^{(88)}$. Entretanto, muitos casos escapam do diagnóstico conclusivo da infecção por $C$. cellulosae. As técnicas de imagem, TC ou RM, não conseguem detectar os cisticercos alojados na cisterna basal subaracnoide ou os parasitas em fase de degeneração ou pré-calcificação.
Além disso, o elevado custo dessas tecnologias impede que muitos países endêmicos tenham acesso a esse tipo de diagnóstico ${ }^{(32)}$. Portanto, os testes laboratoriais são essenciais para o diagnóstico da neurocisticercose.

\section{Pesquisa de anticorpos específicos}

Um dos primeiros testes para o diagnóstico da neurocisticercose, reação de fixação de complemento, foi descrita por Weinberg, em 1909. A técnica foi realizada no soro de três carneiros parasitados por Cysticercus tenuicollis. Posteriormente, em 1911, Moses utilizou a reação para pesquisar anticorpos no soro e no liquor de pacientes com C. cellulosa $e^{(81)}$. No entanto, a sua utilização no diagnóstico é limitada por apresentar baixa sensibilidade $(48 \%)^{(65)}$.

A partir da década de 1960-1970, as reações de imunofluorescência indireta (IFI) e hemaglutinação indireta (HA) foram padronizadas para o diagnóstico da neurocisticercose, sendo amplamente utilizadas e consideradas ainda hoje métodos importante para o diagnóstico. A técnica de IFI foi desenvolvida por Machado et al. (1973), utilizando antígenos de $C$. cellulosae fixados à lâmina ${ }^{(50)}$.

Segundo Pialarissi et al., a sensibilidade e a especificidade foi de $97,6 \%$ e $98,9 \%$, respectivamente, na reação de IFI em amostras de liquor ${ }^{(65)}$. Outros autores encontraram sensibilidade e especificidade em torno de $80 \%$ nessas

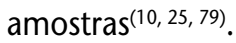

A reação de HA foi inicialmente padronizada com hemácias humanas como suporte para o antígeno, posteriormente substituídas por hemácias de animais, como carneiro ${ }^{(83,84)}$ e ganso ${ }^{(25)}$. A sensibilidade da reação foi de $81 \%$ em amostras de liquor e $85 \%$ em amostras de soro ${ }^{(25,83,84)}$.

As técnicas imunoenzimáticas apresentaram melhor desempenho no diagnóstico da cisticercose quando comparadas com as técnicas de IFI ou $H A^{(19,59,65)}$. A técnica imunoenzimática (ELISA) vem sendo descrita para a detecção de anticorpos específicos e antígenos de cisticerco circulantes em amostras de fluidos biológicos, incluindo soro, liquor ou urina.

A maioria dos trabalhos publicados reporta o uso do antígeno homólogo C. Cellulosae, no entanto, a dificuldade para a obtenção de antígeno adequado pelo método de extração dos cisticercos, a partir de suínos naturalmente infectados, estimulou a procura por outras fontes de antígenos. Destas, destacam-se duas alternativas: Cysticercus longicollis, cisticerco de $T$. crassiceps e Cysticercus bovis, cisticerco de T. saginata. 
T. crassiceps é um parasito de fácil manutenção experimental, sendo mantido por reprodução assexuada em peritônio de camundongo. A demonstração de reações cruzadas observadas entre os antígenos de cisticercos das espécies de Taenia sugere que os parasitas partilham epítopos importantes. Vários estudos descrevem a aplicação desses antígenos heterólogos no diagnóstico imunológico da cisticercose humana ${ }^{(87)}$.

Os antígenos empregados para a detecção de anticorpos específicos evoluiram de extrato antigênico bruto para frações antigênicas altamente purificadas e antígenos recombinantes, resultando no aumento da sensibilidade $\mathrm{e}$ da especificidade do teste.

\section{Antígeno homólogo}

Quanto ao uso do antígeno homólogo, obtido do cisticerco C. cellulosae, destacam-se extrato bruto, proteínas de excreção/secreção, proteínas do escólex e proteínas do fluído vesicular.

De um modo geral, o antígeno bruto e os antígenos de secreção/excreção apresentaram menor desempenho diagnóstico no teste imunoenzimático para pesquisa de anticorpos em amostras séricas. A sensibilidade variou de $76 \%$ a $100 \%$ e a especificidade, de $88 \%$ a $100 \%(20,21,44,45,51,54-56,72,76,94)$.

As proteínas do escólex são bastante específicas (100\%) e a sensibilidade variou de $89 \%$ a $100 \%{ }^{(20,45)}$. As frações proteicas purificadas por eletroeluição, a partir do gel de poliacrilamida, apresentaram alta sensibilidade: $100 \%$ para o antígeno de $100 \mathrm{kDa}$ e $95 \%$ para as frações de $26 \mathrm{kDa}$ e $95 \mathrm{kDa}^{(45)}$.

O fluido vesicular também apresentou alta sensibilidade. A maioria dos estudos detectou sensibilidade de $90 \%(20,21,44,54,76,94)$, exceto um, que reportou sensibilidade de $81 \%{ }^{(56)}$. A especificidade variou de $86 \%$ a $100 \%(20,21,44,54,76,94)$.

Nos pacientes com neurocisticercose, a proteína de $53 \mathrm{kDa}$ do fluido vesicular apresentou especificidade de $98 \%$. A sensibilidade variou de acordo com a presença de cistos, sendo de $96 \%$ quando o paciente apresentava dois ou mais cistos e de $76 \%$ nos pacientes com um cisto único ${ }^{(94)}$. As glicoproteínas de 10 a $26 \mathrm{kDa}$ de fluido vesicular foram purificadas por focalização isoelétrica em $\mathrm{pH} 9,2$ a 9,6, apresentando sensibilidade e especificidade de $100 \%{ }^{(44)}$.

Poucos trabalhos reportam sobre a pesquisa de anticorpos específicos no liquor por ELISA, utilizando o antígeno homólogo. Os antígenos do extrato bruto e da secreção/ excreção apresentaram sensibilidade de $64 \%$ a $92 \%$ e especificidade de $96 \%$ a $99 \%{ }^{(20,55,72)}$. Os antígenos do escólex e do fluido vesicular apresentaram alta sensibilidade, respectivamente, de $90 \%$ e $100 \%$; a especificidade foi de $100 \%$ e $99 \%{ }^{(20)}$.

De um modo geral, as frações antigênicas obtidas do escólex e do fluido vesicular mostram melhores resultados na detecção de anticorpos específicos em amostras de soro ou liquor.

Atualmente, o Enzyme-Linked Immunoelectrotransferblot (EITB) é considerado um dos testes imunológicos mais confiáveis para o diagnóstico da cisticercose e da neurocisticercose. O teste é preparado com antígenos (frações de glicoproteína) purificados por cromatografia de lentil lectina desenvolvidos no Center for Disease Control, nos Estados Unidos (CDC-USA). A avaliação inicial desse ensaio indica sensibilidade de $98 \%$ e especificidade de $100 \%$ em amostras de soro e liquor ${ }^{(82)}$. Outros estudos reportam variação na sensibilidade de $86 \%$ a $100 \%$ no soro e de $81 \%$ a $100 \%$ no liquor, enquanto a variação da especificidade foi de $93 \%$ a $100 \%$ em ambos os tipos de amostras ${ }^{(54,67,89)}$.

O EITB tem ajudado na identificação de frações antigênicas para a detecção de anticorpos anti-C. cellulosae. A frações menores que $25 \mathrm{kDa}$, mais especificamente as de 18 , 14 e 13 kDa, são consideradas frações específicas, podendo ser usadas para detecção de anticorpos no soro e no liquor de pacientes com neurocisticercose $\mathrm{e}^{(64,66,78,82)}$. Porém, a utilização desse teste em pacientes com neurocisticercose na forma inativa pode apresentar baixa sensibilidade devido à não reatividade aos peptídios $13 \mathrm{kDa}$ e $14 \mathrm{kDa}$, marcadores considerados específicos de C. cellulosae $e^{(78)}$.

\section{Antígeno heterólogo}

Um dos primeiros estudos do antígeno alternativo de T. crassiceps foi realizado na Alemanha e publicado em 1989. Os autores purificaram o fluido vesicular de $T$. crassiceps por cromatografia de afinidade, utilizando soro de coelho imunizado com $T$. solium. A fração purificada apresentou nove antígenos de reatividade cruzada com $T$. solium, cujo peso molecular predominante foi de 22, 25, 32 e $45 \mathrm{kDa}$. Nas técnicas como ELISA para detecção de anticorpos em amostras séricas de pacientes com diagnóstico confirmado de neurocisticercose, a sensibilidade foi comparável com o antígeno homólogo (fluido vesicular de T. solium), indicando o potencial de aplicação do antígeno heterólogo purificado ${ }^{(46)}$. 
No Brasil, a partir da década de 1990, Vaz et al. foram os pioneiros que realizaram amplos estudos com o antígeno alternativo de $T$. crassiceps. Inicialmente, analisaram-se diferentes frações antigênicas de $T$. crassiceps, incluindo a membrana e o fluido vesicular, em comparação com o antígeno homólogo, os quais foram analisados em diferentes técnicas, como $\mathrm{HA}^{(25)}$, Dot-blot, ELISA e Imunoblot ${ }^{(12,13,25,53,85,86)}$. Posteriormente, foi utilizado o antígeno do fluido vesicular ${ }^{(14,43)}$ identificando-se o potencial diagnóstico das frações de baixo peso molecular, 14 e $18 \mathrm{kDa}^{(62)}$, para os quais foram produzidos anticorpos monoclonais ${ }^{(23,24)}$. O antígeno glicoproteína de $14 \mathrm{kDa}$ (GP14) purificado por cromatografia de afinidade foi caracterizado e aplicado no sorodiagnóstico da neurocisticercose ${ }^{(63,64)}$.

No estudo comparativo de antígeno homólogo e heterólogo, os resultados descritos são diversos. Bueno et al. reportam maior sensibilidade para o antígeno heterólogo, tanto para amostras de soro como para amostras de liquor. A especificidade foi equivalente para os dois tipos de antígenos ${ }^{(13)}$. Outro estudo, de Barcelos et al., encontrou maior sensibilidade e especificidade para o extrato antigênico homólogo ${ }^{(9)}$. O teste de ELISA, empregando o fluido vesicular, apresentou desempenho diagnóstico similar para os dois tipos de antígenos, homólogo e heterólogo, com sensibilidade de $91 \%$ e especificidade de $95 \%$ a $97 \%\left({ }^{(8,80)}\right.$.

As principais frações antigênicas do cisticerco de $T$. crassiceps apresentam peso molecular de 13 a $19 \mathrm{kDa}^{(13,71)}$. As frações antigênicas de 18 e 14 kDa purificadas por cromatografia de afinidade mostraram no ELISA sensibilidade de $100 \%$ e especificidade de $99 \%{ }^{(24)}$. Em outro estudo, a fração GP14 de $T$. crassiceps apresentou sensibilidade de $95 \%$ e especificidade de $99 \%$ na reação de Western Blot (WB) ${ }^{(63)}$. Os peptídeos da GP14 de T. crassiceps apresentam homologia parcial com os peptídeos do cisticerco de $T$. solium $^{(64)}$. O cisticerco de $T$. saginata também vem sendo explorado como fonte de antígeno para uso diagnóstico da cisticercose humana.

O grupo de Costa-Cruz da Universidade Federal de Uberlândia em Minas Gerais vem realizando estudos com extrato salino e frações antigênicas de metacestódio de $T$. saginata em testes imunoenzimáticos para detecção de anticorpos específicos em amostras de soro e liquor de pacientes com neurocisticercose. Os autores observaram que os marcadores imunodominantes se encontram na fração hidrofóbica, quando utilizado o detergente Triton-X114 na extração(35). Na purificação do extrato salino por cromatografia de afinidade com jacalina ou concanavalina $A$, foi detectada melhor reatividade antigênica na fração não ligada às lectinas ${ }^{(58,60)}$. Nas amostras de liquor, a fração não ligada à jacalina apresentou sensibilidade de $92 \%$ e especificidade de $100 \%{ }^{(58)}$, enquanto nas amostras de soro, as frações purificadas apresentaram sensibilidade de $90 \%$ a $95 \%$ e especificidade de $83 \%$ a $93 \%(35,60)$. A análise das proteínas não ligadas à concanavalina A por WB revelou que as frações 64 a $68 \mathrm{kDa}$ apresentam sensibilidade e especificidade de $100 \%{ }^{(60)}$.

\section{Antígeno recombinante e sintético}

Os antígenos recombinantes descritos foram produzidos em Escherichia coli ou em células eucarióticas, neste caso empregando o sistema baculovírus. O sistema E. coli é de fácil manipulação e geralmente fornece alto rendimento a baixo custo, porém produz a proteína sem glicosilação. Por outro lado, o sistema de expressão em células eucarióticas possibilita a síntese de moléculas proteicas mais complexas que requerem modificações pós-traducionais, incluindo a glicosilação, e vários antígenos nativos estudados são glicoproteínas.

Ferrer et al. clonaram o gene que codifica para a proteína de adesão da oncosfera de $T$. saginata de $18 \mathrm{kDa}$ e produziram os antígenos recombinantes nos sistemas baculovírus (HP6-bac) e E. coli, esta em fusão com glutationa S-transferase (GST) (HP6-GST). Ambos os antígenos apresentaram baixa sensibilidade. Esta, no antígeno HP6-GST, foi de $81 \%$ no soro e $73 \%$ no liquor, enquanto para o antígeno HP6-bac a sensibilidade foi de $77 \%$ nos dois tipos de amostras ${ }^{(26)}$. Quanto aos antígenos recombinantes de $T$. solium descritos, destacam-se os antígenos recombinantes de $8 \mathrm{kDa}$, Ts8B(26, 28), $10 \mathrm{kDa} a^{(18)}, 14 \mathrm{kDa}, \mathrm{TS} 14^{(36,37,77)}, 24$ $\mathrm{KDa}, \mathrm{TS} 24^{(39)}$, TS24H e domínio hidrofílico extracelular do TS24(49), além da gliporoteína de 50 kDa e GP50(38).

$\mathrm{O}$ antígeno recombinante de $10 \mathrm{kDa}$ foi produzido em E. coli e analisado pela técnica de WB com 190 amostras séricas de pacientes com neurocisticercose e 180 amostras controle, incluindo soros de indivíduos sadios e de pacientes com outras parasitoses. A sensibilidade foi de $97 \%$ e a especificidade de $98 \%{ }^{(18)}$. Posteriormente, esse antígeno foi produzido em sistema baculovírus e utilizado no ELISA para análise de soro e liquor de 45 casos de neurocisticercose; a sensibilidade e a especificidade foram, respectivamente, de $94 \%$ e $96 \%(47)$.

O grupo de Tsang em Atlanta, Estados Unidos, clonou e produziu os antígenos recombinantes T24, T24H e GP50, todos no sistema baculovírus. O desempenho diagnóstico 
foi avaliado em amostras séricas ou de liquor de pacientes com neurocisticercose. O antígeno recombinante GP50 apresentou sensibilidade entre $90 \%$ a $99 \%$ e especificidade entre $94 \%$ a $100 \%$ em amostras de soro ${ }^{(15,38,48)}$. Na análise de 64 amostras de liquor, o antígeno GP50 apresentou sensibilidade e especificidade de $100 \%{ }^{(15)}$. O antígeno T24 apresentou sensibilidade de $94 \%$ e especificidade de 98\% ${ }^{(39)}$, enquanto o antígeno $\mathrm{T} 24 \mathrm{H}$ mostrou sensibilidade variando de $94 \%$ a $97 \%$ e especificidade de $99 \%(40,41,48)$.

O antígeno TS14 foi clonado e, após, sintetizado (sTS14), apresentando resultado promissor na análise de amostra de soro de pacientes com cisticercose ${ }^{(36)}$. O antígeno recombinante em fusão com histidina (His-TS14) foi produzido em E. colie analisado por ELISA com amostras de soro e liquor de pacientes com neurocisticercose e amostras controle. Na amostra sérica, a sensibilidade foi de $97 \%$ e nenhuma reatividade foi observada nas amostras do grupo controle ou de pacientes com outras parasitoses, como doença de Chagas ou esquistossomose. Tanto a sensibilidade quanto a especificidade foi de $100 \%$ na análise de liquor ${ }^{(77)}$.

$\mathrm{O}$ antígeno Ts8B foi produzido no sistema baculovírus, também em fusão com GST (GST-Ts8B) e expresso em $E$. coli. Na análise de amostras de liquor e de soro de pacientes com neurocisticercose ativa por ELISA ambos os antígenos apresentaram sensibilidade de $97 \%$, enquanto a especificidade foi de 95\% para Ts8B e de 93\% para GST-Ts8B. O desempenho diagnóstico similar dos antígenos, produzidos em $E$. coli ou células eucarióticas, sugere que o epítopo imunodominante do Ts8B seja predominantemente proteico ${ }^{(28)}$. Esses resultados indicam a GP50 e o TS14 como potenciais marcadores para pesquisa de anticorpos específicos em liquor no diagnóstico laboratorial da neurocisticercose.

Em relação aos antígenos sintéticos, alguns da família de proteínas de $8 \mathrm{kDa}$ foram sintetizados, incluindo TS14, TS18, TSRS1, TSRS2 e algumas variantes ${ }^{(37,75)}$. O antígeno sintético STSR1 apresentou sensibilidade e especificidade de $100 \%$ na análise de 34 soros de pacientes com cisticercose e 49 soros controles por ELISA ${ }^{(37)}$. O antígeno sTS18var1 foi analisado em amostras de soro e liquor de pacientes com neurocisticercose, apresentando sensibilidade de $90 \%$ em ambos os tipos de amostras e especificidade de $90 \%$ e $98 \%$, respectivamente, no soro e no liquor ${ }^{(15)}$. Esse antígeno foi empregado no test Quick ELISA para análise de amostras séricas, apresentando sensibilidade de $94 \% \mathrm{e}$ especificidade de $96 \%{ }^{(48)}$.

Scheel et al. analisaram o desempenho diagnóstico de quatro antígenos sintéticos: sTS14, sTS18var1, sTSRS1 e
sTSRS2var1. Todos os quatro apresentaram baixa sensibilidade no ELISA, enquanto no WB o desempenho foi similar ao teste de referência EITB ${ }^{(75)}$. A diferença observada nos resultados pode ser decorrente da aderência dessas moléculas no suporte sólido e da disposição do epítopo para interação com o anticorpo específico, pois as proteínas síntéticas são de tamanho pequeno e não apresentam a estrutura da proteína nativa. De modo geral, o desempenho dos antígenos recombinantes parece ser mais promissor que os antígenos sintéticos, além do menor custo para a sua produção.

\section{Detecção de antígeno circulante}

A detecção de antígeno circulante em diferentes amostras biológicas (liquor, soro ou urina) tem sido avaliada como potencial marcador para o diagnóstico da doença ativa e para o monitoramento do tratamento da neurocisticercose. Na maioria da literatura estudada, a determinação de antígeno em amostra biológica foi realizada por ELISA, sendo empregado anticorpo policlonal desenvolvido para antígenos de fluido vesicular do cisticerco de T. crassiceps $^{(61)}$ ou anticorpo monoclonal desenvolvido para antígenos de secreção/excreção e de superfície do cisticerco de T. saginat $(11,17,29-31,70)$.

Os níveis elevados de antígenos detectados por ELISA foram proporcionais ao número de cisticercos viáveis e a presença de cisticercos degenerados e/ou calcificados estava relacionada com níveis baixos de antígenos circulantes. A sensibilidade é menor nos casos de infecção por cisto único ${ }^{(30,70)}$.

A localização do cisticerco é outro fator determinante na positividade do teste para pesquisa de antígeno. Quando a localização do cisto é subaracnoide, na base do cérebro, ou ventricular, observa-se alto índice de detecção de antígeno no liquor ou no soro. Por outro lado, os antígenos não foram detectados quando o cisto estava localizado no parênquima ou nos sulcos do espaço subaracnoidal ${ }^{(11,29,54)}$.

Pardini et al. detectaram antígenos em liquor de pacientes com neurocisticercose por ELISA empregando anticorpo policlonal desenvolvido para antígenos de baixo peso molecular (menor que $30 \mathrm{kDa}$ ) de fluido vesicular do cisticerco de $T$. crassiceps. O teste apresentou sensibilidade de $95,8 \%$ e especificidade de $100 \%{ }^{(61)}$. Outros estudos que aplicaram essa técnica reportaram a detecção de antígeno em $47 \%$ a $57 \%$ dos pacientes com neucisticercose $\mathrm{e}^{(1,2)}$. Os autores consideraram que a baixa sensibilidade pode estar 
relacionada com a localização dos cisticercos, pois na maioria dos pacientes o parasita estava localizado no parênquima cerebral em áreas hemisféricas superficiais, sem contato com o liquor ${ }^{(2)}$. Nos estudos realizados com anticorpo monoclonal, a sensibilidade foi de $85 \%$ a $86 \%$ e a especificidade de $92 \%$ a $100 \%$, em amostras séricas ${ }^{22,31)}$. No liquor, de modo geral, a sensibilidade variou entre $86 \%$ a $91 \%(11,29,30,54)$ e a especificidade foi de $100 \%{ }^{(54)}$. O antígeno foi detectado em $100 \%$ das amostras de liquor de pacientes com o cisto viável localizado na região subaracnoide ou ventricular e também nos casos com dois ou mais cistos ${ }^{(30,70)}$. A sensibilidade foi menor em pacientes que apresentavam cistos viáveis intraparênquima, $60 \%$ no soro e $73 \%$ no liquor ${ }^{(70)}$.

A detecção de antígeno, tanto em soro como no liquor, possibilita a discriminação entre a neurocisticercose ativa e inativa. Nos pacientes com cistos calcificados, o antígeno foi detectado em $14,3 \%$ das amostras de soro e em $22,6 \%$ a $28,6 \%$ de liquor ${ }^{(54,70)}$. A pesquisa de antígeno na urina de pacientes com neurocisticercose realizada por ELISA empregando anticorpo monoclonal apresentou sensibilidade de $92 \%$ para os casos com parasitas viáveis e de $62,5 \%$ nos pacientes com um único cisto. $\mathrm{O}$ antígeno foi detectado na urina de $17 \%$ dos pacientes com cisto calcificado. $\mathrm{Na}$ análise de amostras pareadas de 19 indivíduos, observou-se uma forte correlação entre os níveis de antígenos no soro e na urina ${ }^{(17)}$.

A detecção de antígenos por ELISA empregando anticorpo monoclonal vem sendo avaliada também como marcador para monitoramento terapêutico. Os resultados mostram excelente correlação entre a presença de antígeno circulante no soro e a de cistos viáveis no cérebro. Nos pacientes curados, foi observado negativação ou redução significante nos níveis de antígenos circulantes em até três meses após o tratamento efetivo. Os resultados indicam que a detecção de antígenos no soro pode ser uma ferramenta de grande utilidade para o monitoramento da doença, após a terapia antiparasitária, de pacientes com formas graves de neurocisticercose ${ }^{(11,29,30,57) \text {. }}$

A detecção de antígenos é um forte indicador de neurocisticercose ativa, inflamatória e com múltiplos cistos, podendo ser de particular valor na avaliação de pacientes sintomáticos, bem como no monitoramento do tratamento.

\section{Teste rápido}

Foram descritos testes rápidos e de fácil execução para pesquisa de anticorpos específicos. O teste de aglutinação em látex aplicado na análise de liquor apresentou sensibilidade de $89,5 \%$ e especificidade de $75 \%{ }^{(69)}$. O teste imunocromatográfico magnético empregando o antígeno recombinante rT24H foi desenvolvido para detecção de anticorpos específicos para o diagnóstico da neurocisticercose. A sensibilidade do teste foi de $93,9 \%$ na análise de amostras séricas de pacientes com dois ou mais cistos viáveis no cérebro e a especificidade foi de $98,9 \%{ }^{(40)}$.

\section{Técnicas moleculares}

Os genes alvos mais explorados na reação em cadeia da polimerase (PCR) para o diagnóstico da teníase e da cisticercose humana são gene cox1 do ácido desoxirribonucleico (DNA) mitocondrial (subunidade 1 do citocromo $\mathrm{c}$ oxidase e citocromo b) ${ }^{(52,90-92)}$; gene Tso31 que codifica para a proteína específica Tso31 da oncosfera de $T$. solium ${ }^{(52)}$; e gene pTsol9, elemento altamente repetitivo do genoma de $T$. solium ${ }^{(4,54,93)}$.

A PCR multiplex para amplificação dos genes do citocromo c e b possibilitou o diagnóstico diferencial de $T$. saginata, $T$. asiática e T. solium genótipo asiático e genótipo americano-africano, quando aplicada em amostras de fezes de pacientes com teníase ${ }^{(90,91)}$. Nas amostras de biópsia, com resultado inconclusivo nos exames histopatológicos, a sequência de nucleotídeos do gene amplificado por PCR identificou o agente etiológico como $T$. solium genótipo asiático ${ }^{(52,9092)}$. Em outro estudo, a PCR foi utilizada na identificação de cisticercos (tipos racemoso e celulose) em material de biópsia de pacientes com neurocisticercose. Inicialmente, o gene da região ITS1 ribossômico foi amplificado e sequenciado; posteriormente, o DNA mitocondrial cox1 foi amplificado na PCR confirmatória ${ }^{(42)}$. A nested-PCR-Tso31 apresentou sensibilidade de $97 \%$ a $100 \%$ e especificidade de $100 \%$ em amostras de fezes de pacientes de área endêmica ${ }^{(52)}$.

Quanto à aplicação da PCR no diagnóstico da neurocisticercose, três trabalhos se destacam e todos reportam a amplificação do gene pTsol9(4,54,93). No primeiro trabalho, desenvolvido no Brasil por Almeida et al., o resultado da PCR foi positivo em $96,7 \%$ (29/30) das amostras de liquor, destacando a sua importância como um método adicional para o diagnóstico da neurocisticercose. Porém, a PCR foi negativa em um paciente previamente diagnosticado com neurocisticercose por RM pela presença de anticorpo no liquor. Este indivíduo apresentava C. racemosus, intensa reação meníngea e múltiplos cistos calcificados no parênquima ${ }^{(4)}$. Outro estudo reportou a sensibilidade de $90 \%$ a $100 \%$, dependendo do 
estágio da doença e da localização do cisto. A especificidade foi variável, $80 \%$ para controles de procedência mexicana e $100 \%$ para controles de procedência francesa. No entanto, a aplicabilidade dessa técnica em amostras de liquor para monitoramento pós-tratamento precisa ser avaliada, pois detecta o parasita independente da sua viabilidade ${ }^{(54)}$.

Recentemente, a PCR em tempo real, TaqMan, foi desenvolvida para o diagnóstico confirmatório de neurocisticercose e monitoramento após o tratamento. $\mathrm{O}$ teste apresentou especificidade de $100 \%$ e, na análise do liquor em nove pacientes com diagnóstico de neurocisticercose, o resultado foi positivo em sete pacientes (83,3\%). O DNA do parasita foi detectado no liquor de alguns indivíduos vários meses depois do tratamento. Os sintomas também foram persistentes nesses pacientes, sugerindo que as larvas podem não ter sido totalmente eliminadas pela terapêutica(93).

Os estudos mostram que o gene pTsol9 é um importante marcador para a detecção de DNA de $T$. solium no liquor de pacientes com neurocisticose. Contudo, novos genes alvos poderão ser explorados quanto ao seu potencial no diagnóstico molecular da neurocisticercose e o Projeto Genoma da Taenia solium em andamento no México ${ }^{(3)}$ é uma perspectiva nessa direção.

\section{Novas abordagens}

Entre as novas abordagens citadas na literatura, destacam-se análise do transcriptoma do cisticerco de $T$. solium, seleção de clones a partir de bibliotecas de display de peptídeos e estudo do proteoma do cisticerco para identificação de potenciais antígenos.

A análise do transcriptoma do cisticerco de $T$. solium foi realizada pela técnica de Open Reading Frames Expressed Sequence Tags (ORESTES), que identifica a sequência a partir da região central dos genes. Foram sequenciados 2.857 nucleotídeos e anotadas 191 sequências codificadoras, cujas funções estão relacionadas com processos biológicos, funções moleculares e componentes estruturais. Destes, 51 ORESTES apresentaram similaridade com antígenos conhecidos, incluindo um gene que codifica para o antígeno de superfície TEG-Tsol, um potencial candidato para desenvolvimento de imunodiagnóstico e vacinas ${ }^{(5)}$.

No estudo de seleção de peptídeo imunogênico a partir de biblioteca randômica de display de peptídeos, foi selecionado um clone (NC-4-1) cujo peptídeo apresentou sensibilidade de $100 \%$ e especificidade de $94,5 \%$ com soros de pacientes com neurocisticercose ${ }^{(68)}$. Recentemente, a abordagem proteômica vem sendo explorada na identificação de novos marcadores com aplicação no imunodiagnóstico. A separação das proteínas em gel bidimensional (2D) e a realização do WB com anticorpos de pacientes com diagnóstico de neurocisticercose possibilita a identificação dos antígenos (spots) reagentes. Os spots de interesse isolados a partir do gel 2D são identificados e sequenciados por espectrometria de massa. Uma vez sequenciado, esse antígeno poderá ser expresso como proteína recombinante para aplicação nos testes diagnósticos.

O estudo de proteínas solúveis do extrato bruto de cisticerco de $T$. solium por WB 2D e análise por espectrometria de massa identificou um novo antígeno de $27 \mathrm{kDa}$, o Tsol-27(73). Este, recombinante, foi utilizado no teste de Imunoblot para análise de amostras de pacientes com epilepsia e suspeita de neurocisticercose, com sensibilidade de $86,7 \%$ e especificidade de $97,8 \%{ }^{(74)}$.

\section{Considerações finais}

A detecção ou a demonstração do agente etiológico pelas técnicas de imagem é definitiva no diagnóstico da neurocisticercose. Entretanto, em muitos casos, os testes laboratoriais ainda são de fundamental importância como método complementar do diagnóstico.

Trabalhos recentes mostram que os potenciais marcadores antigênicos apresentam baixo peso molecular, menor que $50 \mathrm{kDa}^{(55,61,82)}$, e os antígenos recombinantes parecem ser promissores ${ }^{(15,27,39,49,77)}$. Aparentemente, existe uma associação entre neurocisticercose ativa e presença de anticorpos contra frações antigênicas de peso molecular menor que $50 \mathrm{kDa}^{(55)}$. Quanto à pesquisa de antígeno de cisticerco no liquor, os trabalhos mostram sensibilidade de $91 \%$ a $95 \%(29,61)$ e demonstram maior correlação com as formas viáveis e a localização do cisticerco, subaracnoide e intraventricular ${ }^{(29,70)}$. As técnicas moleculares também apresentam resultados promissores ${ }^{(4,54)}$.

Todavia, nenhum desses testes está disponível comercialmente. Não existe no mercado um kit comercial padronizado para a detecção de antígeno do cisticerco em amostras de liquor ou para o diagnóstico molecular da neurocisticercose.

Atualmente, no Brasil, apenas dois kits de ELISA para o diagnóstico de cisticercose foram aprovados e estão com 
o registro em validade na $A N V I S A^{(7)}$ : um de procedência nacional para detecção de anticorpos imunoglobulina da classe $\mathrm{G}(\mathrm{lg} G)$ anticisticerco em amostras de liquor e outro de fabricação alemã, para detecção de anticorpos $\lg G$ anti T. solium e cisticerco em amostras de soro, este último com sensibilidade de $100 \%$ e especificidade de $93 \%$, segundo o fabricante.

Neste contexto, os estudos futuros poderão ser direcionados para o desenvolvimento de testes aplicáveis, tanto em amostras de liquor como de soro, considerando as seguintes características: (i) apresentar sensibilidade e especificidade próximo de 100\%; (ii) ter um marcador diferencial para cisticercose ativa e calcificada; além de (iii) marcador para monitoramento de tratamento.

Os antígenos de baixo peso molecular apresentam potencial para utilização nos testes imunológicos, além disso, novos marcadores antigênicos poderão ser explorados, bem como novos genes alvos para a aplicação nas técnicas moleculares.

A abordagem proteômica é promissora para a identificação de novos marcadores e poderá ser direcionada para a identificação de proteínas específicas do escólex de $T$. solium e do fluido vesicular do cisticerco homólogo ou heterólogo, uma vez que as proteínas parcialmente purificadas dessas fontes de antígeno têm apresentado melhor desempenho no imunodiagnóstico da neurocisticercose.

\section{Agradecimentos}

À Fundação de Desenvolvimento Administrativo (FUNDAP) pela bolsa concedida à Sílvia Y. Togoro, e à Dra. Jane H. Atobe pela revisão do manuscrito.

\section{Referências}

1. ABRAHAM, R. et al. Taenia antigens detection in the cerebrospinal fluid of patients with neurocysticercosis and its relationship with clinical activity of the disease. Arq Neuropsiquiatr, v. 62, p. 756-60, 2004.

2. ABRAHAM, R. et al. Neurocysticercosis: relationship between Taenia antigen levels in CSF and MRI. Arq Neuropsiquiatr, v. 68, p. 7-11, 2010.

3. AGUILAR-DÍAZ, H. etal. The genome project of Taenia solium. Parasitology International, v. 55, p. S127-S30, 2006.

4. ALMEIDA, C. R. et al. Taenia solium DNA is present in the cerebrospinal fluid of neurocysticercosis patients and can be used for diagnosis. Eur Arch Psychiatry Clin Neurosci, v. 256, p. 307-10, 2006.

5. ALMEIDA, C. R. et al. Transcriptome analysis of Taenia solium cysticerci using Open Reading Frame ESTs (ORESTES). Parasit Vectors, v. 2, p. 35, 2009.

6. AMARAL, L. et al. Ununsual manifestations of neurocysticercosis in MR imaging: analysis of 172 cases. Arq Neuropsiquiatr, v. 61, p. 533-41, 2003.

7. ANVISA, 2012. Agência Nacional de Vigilância Sanitária. Disponível em: <http://www7.anvisa.gov.br/datavisa/ Consulta_Produto_correlato/consulta_correlato.asp >. Acesso em: 10 jan. 2012.

8. ARRUDA, G. C. et al. Evaluation of Taenia solium and Taenia crassiceps cysticercal antigens for the serodiagnosis of neurocysticercosis. Trop Med Int Health, v. 10, p. 1005-12, 2005.

9. BARCELOS, I. S. et al. Detection of IgG in cerebrospinal fluid for diagnosis of neurocysticercosis: evaluation of saline and SDS extracts from Taenia solium and Taenia crassiceps metacestodes by ELISA and immunoblot assay. Trop Med Int Health, v. 6, p. 219-26, 2001.

10. BASSI, G. E. et al. A reação imunoenzimática para cisticercose no líquido cefalorraquiano - considerações sobre o limiar de reatividade. Rev Bras Patol Clin, v. 27, p. 49-52, 1991.

11. BOBES, R. J. et al. Subarachnoidal and intraventricular human neurocysticercosis: application of an antigen detection assay for the diagnosis and follow-up. Trop Med Int Health, v. 11, p. 943-50, 2006.

12. BUENO, E. C. et al. Neurocysticercosis: detection of IgG, IgA and IgE antibodies in cerebrospinal fluid, serum and saliva samples by ELISA with Taenia solium and Taenia crassiceps antigens. Arq Neuropsiquiatr, v. 58, p. 18-24, 2000.

13. BUENO, E. C. et al. Specific Taenia crassiceps and Taenia solium antigenic peptides for neurocysticercosis immunodiagnosis using serum samples. J Clin Microbiol, v. 38, p. 146-51, 2000.

14. BUENO, E. C. et al. Antigen-specific suppression of cultured lymphocytes from patients with neurocysticercosis. Clin Exp Immunol, v. 126, p. 304-10, 2001.

15. BUENO, E. C. et al. Application of synthetic 8-kD and recombinant GP50 antigens in the diagnosis of neurocysticercosis by enzyme-linked immunosorbent assay. Am J Trop Med Hyg, v. 72, p. 278-83, 2005.

16. CARPIO, A.; ESCOBAR, A.; HAUSER, W. A. Cysticercosis and epilepsy: a critical review. Epilepsia, v. 39, p. 102540, 1998.

17. CASTILLO, Y. et al. Urine antigen detection for the diagnosis ofhuman neurocysticercosis. Am J TropMed Hyg, v. 80, p. 379-83, 2009.

18. CHUNG, J. Y. et al. A recombinant $10 \mathrm{kDa}$ protein of Taenia solium metacestodes specific to active neurocysticercosis. J Infect Dis, v. 180, p. 1307-15, 1999.

19. COSTA, J. M. et al. Spinal fluid immunoenzymatic assay (ELISA) for neurocysticercosis. Rev Inst Med Trop Sao Paulo, v. 24, p. 337-41, 1982. 
20. COSTA, J. M. Immunoenzymatic test (ELISA) in the diagnosis of neurocysticercosis: study of various antigenic extracts in the detection of IgG antibodies in serum and cerebrospinal fluid samples. Arq Neuropsiquiatr, v. 44, p. 15-31, 1986.

21. DEKUMYOY, P. et al. Neurocysticercosis: utilizing the cystic fluid antigen from Taenia solium metacestodes for diagnosis by IgG-ELISA. Southeast Asian J Trop Med Public Health, v. 31, Suppl. 1, p. 21-5, 2000.

22. DEL BRUTTO, O. H. et al. Proposed diagnostic criteria for neurocysticercosis. Neurology, v. 57, p. 177-83, 2001.

23. ESPINDOLA, N. M. et al. Production of monoclonal antibodies anti-Taenia crassiceps cysticerci with crossreactivity with Taenia solium antigens. Rev Inst Med Trop Sao Paulo, v. 42, p. 175-7, 2000.

24. ESPINDOLA, N. M. et al. Cysticercosis immunodiagnosis using 18- and 14-kilodalton proteins from Taenia crassiceps cysticercus antigens obtained by immunoaffinity chromatography. J Clin Microbiol, v. 43, p. 3178-84, 2005.

25.FERREIRA, A. P. et al. Hemagglutination test for the diagnosis of human neurocysticercosis: development of a stable reagent using homologous and heterologous antigens. Rev Inst Med Trop Sao Paulo, v. 39, p. 29-33, 1997.

26. FERRER, E. et al. Molecular cloning and characterisation of Ts8B1, Ts8B2 and Ts8B3, three new members of the Taenia solium metacestode $8 \mathrm{kDa}$ diagnostic antigen family. Mol Biochem Parasitol, v. 152, p. 90-100, 2007.

27. FERRER, E. et al. Evaluation of recombinant HP6-Tsag, an 18 kDa Taenia saginata oncospheral adhesion protein, for the diagnosis of cysticercosis. Parasitol Res, v. 101, p. 517-25, 2007.

28. FERRER, E. et al. Peptide epitopes of the Taenia solium antigen Ts8B2 are immunodominant in human and porcine cysticercosis. Mol Biochem Parasitol, v. 168, p. 168-71, 2009.

29. FLEURY, A. et al. Detection of HP10 antigen in serum for diagnosis and follow-up of subarachnoidal and intraventricular human neurocysticercosis. J Neurol Neurosurg Psychiatry, v. 78, p. 970-4, 2007.

30. GARCIA, H. H. et al. A specific antigen-detection ELISA for the diagnosis of human neurocysticercosis. The Cysticercosis Working Group in Peru. Trans R Soc Trop Med Hyg, v. 92, p. 411-4, 1998.

31. GARCIA, H. H. et al. Serum antigen detection in the diagnosis, treatment, and follow-up of neurocysticercosis patients. Transactions of the Royal Society of Tropical Medicine and Hygiene, v. 94, p. 673-6, 2000.

32. GARCIA, H. H.; DEL BRUTTO, O. H. Imaging findings in neurocysticercosis. Acta Trop, v. 87, p. 71-8, 2003.

33. GARCIA, H. H.; DEL BRUTTO, O. H. Neurocysticercosis: updated concepts about an old disease. Lancet Neurol, v. 4, p. 653-61, 2005.

34. GARG, R. K. Diagnostic criteria for neurocysticercosis: some modifications are needed for Indian patients. Neurol India, v. 52, p. 171-7, 2004.
35. GONÇALVES, F. A. et al. Hydrophobic fraction of Taenia saginata metacestodes, rather than hydrophilic fraction, contains immunodominant markers for diagnosing human neurocysticercosis. Rev Soc Bras Med Trop, v. 43, p. 254-9, 2010.

36. GREENE, R. M. et al. Taenia solium: molecular cloning and serologic evaluation of 14-and 18-kDa related, diagnostic antigens. J Parasitol, v. 86, p. 1001-7, 2000.

37. HANCOCK, K. et al. Characterization of the 8-kilodalton antigens of Taenia solium metacestodes and evaluation of their use in an enzyme-linked immunosorbent assay for serodiagnosis. J Clin Microbiol, v. 41, p. 2577-86, 2003.

38. HANCOCK, K. et al. Characterization and cloning of GP50, a Taenia solium antigen diagnostic for cysticercosis. Mol Biochem Parasitol, v. 133, p. 115-24, 2004.

39. HANCOCK, K. et al. Characterization and cloning of T24, a Taenia solium antigen diagnostic for cysticercosis. Mol Biochem Parasitol, v. 147, p. 109-17, 2006.

40. HANDALI, S. et al. Development and evaluation of a magnetic immunochromatographic test to detect Taenia solium, which causes taeniasis and neurocysticercosis in humans. Clin Vaccine Immunol, v. 17, p. 631-7, 2010.

41. HANDALI, S. et al. Multiantigen print immunoassay for comparison of diagnostic antigens for Taenia solium cysticercosis and taeniasis. Clin Vaccine Immunol, v. 17, p. 68-72, 2010.

42. HINOJOSA-JUAREZ, A. C. et al. Genetic similarity between cysticerci of Taenia solium isolated from human brain and from pigs. Infect Genet Evol, v. 8, p. 653-6, 2008.

43. ISHIDA, M. M. et al. Serodiagnosis of neurocysticercosis in patients with epileptic seizure using ELISA and immunoblot assay. Rev Inst Med Trop Sao Paulo, v. 48, p. 343-6, 2006.

44. ITO, A. et al. Novel antigens for neurocysticercosis: simple method for preparation and evaluation for serodiagnosis. Am J Trop Med Hyg, v. 59, p. 291-4, 1998.

45. IUDICI NETO, F. et al. Immunodiagnosis of human neurocysticercosis by using semi-purified scolex antigens from Taenia solium cysticerci. Rev Soc Bras Med Trop, v. 40, p. 163-9, 2007.

46. KUNZ, J. et al. Taenia crassiceps metacestode vesicular fluid antigens shared with the Taenia solium larval stage and reactive with serum antibodies from patients with neurocysticercosis. Zentralbl Bakteriol, v. 271, p. 51020, 1989.

47. LEE, E. G. et al. Feasibility of baculovirus-expressed recombinant $10-\mathrm{kDa}$ antigen in the serodiagnosis of Taenia solium neurocysticercosis. Trans $R$ Soc Trop Med Hyg, v. 99, p. 919-26, 2005.

48. LEE, Y. M. et al. Serologic diagnosis of human Taenia solium cysticercosis by using recombinant and synthetic antigens in QuickELISATM. Am J Trop Med Hyg, v. 84, p. 587-93, 2011.

49. LEVINE, M. Z. et al. Development of an enzyme-linked immunoelectrotransfer blot (EITB) assay using two baculovirus expressed recombinant antigens for diagnosis of Taenia solium taeniasis. J Parasitol, v. 93, p. 409-17, 2007. 
50. MACHADO, A. J. et al. Reação de imunofluorescência para a cisticercose com partículas de Cysticercus cellulosae fixadas a lâminas de microscopia. Rev Inst Med Trop, v. 7, p.181-83, 1973.

51. MACHADO, G. A. et al. Assessment of antigenic fractions of varying hydrophobicity from Taenia solium metacestodes for the diagnosis of human neurocysticercosis. Trop Med Int Health, v. 12, p. 1369-76, 2007.

52. MAYTA, H. et al. Nested PCR for specific diagnosis of Taenia solium taeniasis. J Clin Microbiol, v. 46, p. 286-9, 2008.

53. MELO, C. S. et al. Human neurocysticercosis. IgE in cerebrospinal fluid. Arq Neuropsiquiatr, v. 55, p. 8-11, 1997.

54. MICHELET, L. et al. Human neurocysticercosis: comparison of different diagnostic tests using cerebrospinal fluid. J Clin Microbiol, v. 49, p. 195-200, 2011.

55. MOLINARI, J. L. et al. Discrimination between active and inactive neurocysticercosis by metacestode excretory/ secretory antigens of Taenia solium in an enzyme-linked immunosorbent assay. Am J Trop Med Hyg, v. 66, p. 777-81, 2002.

56. MORAKOTE, N. et al. Comparison of cysticercus extract, cyst fluid and Taenia saginata extract for use in ELISA for serodiagnosis of neurocysticercosis. Southeast Asian J Trop Med Public Health, v. 23, p. 77-81, 1992.

57. NGUEKAM, Z. A. P. et al. Follow-up of neurocysticercosis patients after treatment using an antigen detection ELISA. Parasite, v. 10, p. 65-8, 2003.

58. NUNES, D. D. S. et al. Jacalin-unbound fraction of Taenia saginata in immunodiagnosis of neurocysticercosis in human cerebrospinal fluid. Diagn Microbiol Infect Dis, v. 68, p. 259-64, 2010.

59. ODASHIMA, N. S.; TAKAYANAGUI, O. M.; FIGUEIREDO, J. F. Enzyme linked immunosorbent assay (ELISA) for the detection of IgG, IgM, IgE and IgA against Cysticercus cellulosae in cerebrospinal fluid of patients with neurocysticercosis. Arq Neuropsiquiatr, v. 60, p. 400-5, 2002.

60. OLIVEIRA, H. B. et al. Taenia saginata metacestode antigenic fractions without affinity to concanavalin $A$ are an important source of specific antigens for the diagnosis of human neurocysticercosis. Clin Vaccine Immunol, v. 17, p. 638-44, 2010.

61. PARDINI, A. X. et al. Cysticercus antigens in cerebrospinal fluid samples from patients with neurocysticercosis. J Clin Microbiol, v. 39, p. 3368-72, 2001.

62. PARDINI, A. X. et al. Use of Taenia crassiceps cysticercus antigen preparations for detection of antibodies in cerebrospinal fluid samples from patients with neurocysticercosis (Taenia solium). Clin Diagn Lab Immunol, v. 9, p. 190-3, 2002.

63. PERALTA, R. H. et al. Evaluation of an antigen from Taenia crassiceps cysticercus for the serodiagnosis of neurocysticercosis. Acta Trop, v. 83, p. 159-68, 2002.

64. PERALTA, R. H. et al. Taenia crassiceps cysticerci: characterization of the 14-kDa glycoprotein with homologies to antigens from Taenia solium cysticerci. Exp Parasitol, v. 124, p. 295-300, 2010.
65. PIALARISSI, C. S. et al. Comparative study of serological tests in the immunological diagnosis of neurocysticercosis. Rev Inst Med Trop Sao Paulo, v. 29, p. 367-73, 1987.

66. PINTO, P. S. et al. Immunoblot analysis using antigen from Taenia crassiceps cysticerci in the diagnosis of swine cysticercosis. Bol Chil Parasitol, v. 56, p. 36-42, 2001.

67. PROANO-NARVAEZ, J. V. et al. Laboratory diagnosis of human neurocysticercosis: double-blind comparison of enzyme-linked immunosorbent assay and electroimmunotransfer blot assay. J Clin Microbiol, v. 40, p. 2115-8, 2002.

68. RIBEIRO, V. D. S. et al. Selection of high affinity peptide ligands for detection of circulating antibodies in neurocysticercosis. Immunol Lett, v. 129, p. 94-9, 2010.

69. ROCHA, S. M. et al. A rapid latex agglutination test for the detection of anti-cysticercus antibodies in cerebrospinal fluid (CSF). Rev Inst Med Trop Sao Paulo, v. 44, p. 57-8, 2002.

70. RODRIGUEZ, S. et al. Detection of Taenia solium antigens and anti- $T$. solium antibodies in paired serum and cerebrospinal fluid samples from patients with intraparenchymal or extraparenchymal neurocysticercosis. J Infect Dis, v. 199, p. 1345-52, 2009.

71. ROSSI, N. et al. Immunodiagnosis of neurocysticercosis: comparative study of antigenic extracts from Cysticercus cellulosae and Taenia crassiceps. Rev Cubana Med Trop, v. 52, p. 157-64, 2000.

72. SAHU, P. S. et al. Evaluation of an IgG-ELISA strategy using Taenia solium metacestode somatic and excretorysecretory antigens for diagnosis of neurocysticercosis revealing biological stage of the larvae. Acta Trop, v. 110 , p. 38-45, 2009.

73. SALAZAR-ANTON, F.; LINDH, J. Taenia solium: a two-dimensional western blotting method combined with the use of an EST-library for the identification of immunogenic proteins recognized by sera from neurocysticercosis patients. Exp Parasitol, v. 128, p. 371-6, 2011.

74. SALAZAR-ANTON, F.; TELLEZ, A.; LINDH, J. Evaluation of an immunodot blot technique for the detection of antibodies against Taenia solium larval antigens. Parasitol Res, p. 1-5, 2012.

75. SCHEEL, C. M. et al. Serodiagnosis of neurocysticercosis using synthetic 8-kD proteins: comparison of assay formats. Am J Trop Med Hyg, v. 73, p. 771-6, 2005.

76. SHIGUEKAWA, K. Y. et al. ELISA and western blotting tests in the detection of IgG antibodies to Taenia solium metacestodes in serum samples in human neurocysticercosis. Trop Med Int Health, v. 5, p. 443-9, 2000.

77. SILVA, M. R. M. et al. Recombinant expression of Taenia solium TS14 antigen and its utilization for immunodiagnosis of neurocysticercosis. Acta Trop, v. 100, p. 192-8, 2006.

78. SIMAC, C. et al. Use of enzyme-linked immunosorbent assay and enzyme-linked immunoelectrotransfer blot for the diagnosis and monitoring of neurocysticercosis. Parasitol Res, v. 81, p. 132-6, 1995. 
79. SIMONETTI, A. B.; TEIXEIRA, J. Behavior of the indirect immunofluorescence reaction and of cerebrospinal fluid parameters in neurocysticercosis. Arq Neuropsiquiatr, v. 45, p. 33-43, 1987.

80. SUZUKI, L. A. et al. Evaluation of Taenia solium and Taenia crassiceps cysticercal antigens for immunodiagnosis of neurocysticercosis using ELISA on cerebrospinal fluid samples. Rev Soc Bras Med Trop, v. 40, p. 152-5, 2007.

81. TRELLES, J. O.; LAZARTE, J. Cisticercose cerebral: estudio clínico, histopatológico y parasitológico. Rev Neuropsiquiatria, v. 3, p. 393-511, 1940.

82. TSANG, V. C.; BRAND, J. A.; BOYER, A. E. An enzymelinked immunoelectrotransfer blot assay and glycoprotein antigens for diagnosing human cysticercosis (Taenia solium). J Infect Dis, v. 159, p. 50-9, 1989.

83. UEDA, M. et al. Passive haemagglutination test for human neurocysticercosis immunodiagnosis. I. Standardization and evaluation of the passive haemagglutination test for the detection of anti-Cysticercus cellulosae antibodies. Rev Inst Med Trop Sao Paulo, v. 30, p. 51-6, 1988.

84. UEDA, M. et al. Passive haemagglutination test for human neurocysticercosis immunodiagnosis. II--Comparison of two standardized procedures for the passive haemagglutination reagent in the detection of anti-Cysticercus cellulosae antibodies in cerebrospinal fluids. Rev Inst Med Trop Sao Paulo, v. 30, p. 57-62, 1988.

85. VAZ, A. J. et al. Dot-ELISA for the detection of antiCysticercus cellulosae antibodies in cerebrospinal fluid using a new solid phase (resin-treated polyester fabric) and Cysticercus longicollis antigens. Rev Inst Med Trop Sao Paulo, v. 38, p. 391-6, 1996.

86. VAZ, A. J. et al. Immunoblot with cerebrospinal fluid from patients with neurocysticercosis using antigen from cysticerci of Taenia solium and Taenia crassiceps. Am J Trop Med Hyg, v. 57, p. 354-7, 1997.

87. VAZ, A. J. Infecções Parasitárias. In: VAZ, A. J.; TAKEI, K.; BUENO, E. C. (Eds.). Imunoensaios - fundamentos e aplicações: ciências farmacêuticas. Rio de Janeiro: Guanabara Koogan, 2007. p. 188-9.

88. WHITE, A. C. Neurocysticercosis: updates on epidemiology, pathogenesis, diagnosis, and management. Annu Rev Med, v. 51, p. 187-206, 2000.

89. WILSON, M. et al. Clinical evaluation of the cysticercosis enzyme-linked immunoelectrotransfer blot in patients with neurocysticercosis. J Infect Dis, v. 164, p. 1007-9, 1991.

90. YAMASAKI, H. et al. Cysticercosis/taeniasis: recent advances in serological and molecular diagnoses. Southeast Asian J Trop Med Public Health, v. 34, Suppl. 2, p. 98-102, 2003.

91. YAMASAKI, H. et al. DNA differential diagnosis of taeniasis and cysticercosis by Multiplex PCR. J Clin Microbiol, v. 42, p. 548-53, 2004.

92. YAMASAKI, H. et al. Molecular identification of Taenia solium cysticercus genotype in the histopathological specimens. Southeast Asian J Trop Med Public Health, v. 36, Suppl. 4, p. 131-4, 2005.

93. YERA, $H$. et al. Confirmation and follow-up of neurocysticercosis by real-time PCR in cerebrospinal fluid samples of patients living in France. J Clin Microbiol, v. 49, p. 4338-40, 2011.

94. ZIMIC, M. et al. Utility of a protein fraction with cathepsin L-Like activity purified from cysticercus fluid of Taenia solium in the diagnosis of human cysticercosis. Am J Trop Med Hyg, v. 80, p. 964-70, 2009. 